\title{
DESCONOCIMIENTO SOCIAL, EXOTISMO Y DISCRIMINACIÓN RACIAL: REPRESENTACIONES Y PRÁCTICAS HACIA MIGRAN- TES AFRICANOS EN LA SOCIEDAD ARGENTINA
}

\section{Social Ignorance, Exotism and Racial Discrimination: Representations and Practices Towards African Migrants in Argentine Society}

\section{ORLANDO GABRIEL MORALES*}

\author{
Fecha de recepción: 20 de junio de 2017 - Fecha de aprobación: 24 de octubre de 2017
}

\section{Resumen}

Este artículo desarrolla dos cuestiones que consideramos de interés en relación con la integración de migrantes africanos recientes en la sociedad argentina, donde la negritud y la afrodescendencia han sido históricamente negadas e invisibilizadas: sus identificaciones sociales; y las representaciones y prácticas que los construyen como Otros. El corpus de análisis que retoma el artículo corresponde a una investigación desarrollada entre los años 2008 y 2014, que interpeló a través de una aproximación etnográfica, con observación participante y entrevistas abiertas y semi-estructuradas, a un grupo de migrantes procedentes de África y radicados desde la década de 2000 en las ciudades de Buenos Aires y La Plata (Argentina). Con base en ese corpus describimos las identificaciones de los migrantes, en tensión con un imaginario social dominante en la sociedad mayor que representa a las personas socialmente construidas como negras y de origen africano en términos de diferentes, exóticas, desconocidas y objeto de discriminación. Luego avanzamos puntualmente sobre el desconocimiento social, el exotismo y la discriminación racial en tanto representaciones y prácticas recurrentes hacia los migrantes africanos, que entregan elementos de conocimiento sobre las (dis)continuidades de la invisibilización de lo africano y lo negro en Argentina.

Palabras Clave: invisibilización, afroargentinidad, desconocimiento social, discriminación, exotismo

\begin{abstract}
This article develops two issues that we consider of interest in relation to the integration of recent African migrants in Argentine society, where negritude and afrodescendence have historically been denied and made invisible: their social identifications; and the representations and practices that build them as others. The corpus of analysis that takes up the article corresponds to an investigation developed between 2008 and 2014, which intervened through an ethnographic approach, with participant observation and open and semi-structured interviews, to a group of migrants from Africa and settled since the 2000s in the cities of Buenos Aires and La Plata (Argentina). Based on this corpus we describe the identifications of the migrants, in tension with a dominant social imaginary in the larger society that represents people socially constructed as blacks and of African origin in terms of different, exotic, unknown and object of discrimination. Then we advance punctually on social ignorance, exoticism and racial discrimination as representations and recurrent practices towards African migrants, who provide elements of knowledge about the (dis)continuities of the invisibility of the African and the black in Argentina.
\end{abstract}

Keywords: invisibilization, african migration, social ignorance, racial discrimination, exoticism

\footnotetext{
* Dr. en Comunicación. Investigador Asistente, Consejo Nacional de Investigaciones Científicas y Técnicas (CONICET), Mendoza, Argentina. Artículo enmarcado en tesis doctoral y en dos proyectos de investigación: «Etnografía de las organizaciones de migrantes africanos subsaharianos y afrodescendientes en Provincia de Buenos Aires y CABA» (CONICET); «Nuevas alterizaciones, visibilidades y relaciones entre organizaciones de migrantes africanos subsaharianos y afrodescendientes" (Agencia Nacional de Promoción Científica y Tecnológica).Correo-e: omorales@mendoza-conicet.gob.ar, ogabrielmorales@gmail.com
} 


\section{Introducción}

Este trabajo se inscribe en una investigación mayor, desarrollada entre los años 2008 y 2014 , orientada a examinar representaciones sociales de migrantes del África subsahariana y de afrodescendientes, nativos y migrantes, para conocer las modalidades en que estos grupos son construidos como diversos en la sociedad argentina. El interés por este problema de conocimiento surgió frente a la trascendencia social que adquirió un nuevo contingente de migrantes subsaharianos, mayoritariamente senegaleses, que inició su arribo en los años '90 pero alcanzó mayor relevancia cuantitativa y visibilidad social a mediados de la década de 2000 , cuando llegó a encabezar la demanda al Estado de solicitudes de refugio y extendió su presencia en el comercio informal ambulante en centros urbanos y turísticos del país. Ese fenómeno de visibilidad social de los nuevos migrantes «negros» coincidió con una mayor presencia en la arena pública de militantes afrodescendientes que reclamaban para sí un reconocimiento en el marco de la nación argentina.

En el contexto de la investigación a la que referimos se realizaron entrevistas abiertas y semi-estructuradas a un grupo de diez migrantes procedentes de Senegal (8), Togo (1) y Nigeria (1), radicados en las ciudades de La Plata y Buenos Aires. También se mantuvieron conversaciones ocasionales con otros diez migrantes, la mayoría de nacionalidad senegalesa; y se hicieron observaciones con participación (en ocasiones una «observación acompañante». Alioua, 2008) en espacios donde algunos de ellos ejercían su actividad laboral (puestos comerciales instalados en la vía pública o ferias de propiedad privada). La aplicación de todas estas herramientas de investigación siguió los lineamientos de una aproximación etnográfica reflexiva (Ghasarian, 2008) ${ }^{1}$, abierta a problematizar las tensiones entre las perspectivas insider/outsider, las «restitutions $»^{2}$ y los malentendidos interculturales que suelen tener lugar en la situación etnográfica, en tanto juegan un rol productivo para la elaboración de un saber relacional (Katzer \& Morales, 2009). Los materiales obtenidos por esos medios focalizan en la comunicación y en las relaciones sociales de los migrantes y constituyen el insumo de este artículo, que se organiza de la siguiente manera: primero exponemos brevemente un marco teórico que explica y permite interpretar las modalidades históricas de visibilidad de la población de origen africano en la sociedad argentina. En segundo lugar describimos de manera general las identificaciones de los migrantes africanos en su dinámica relacional en la sociedad de acogida. Más adelante, en tres apartados consecutivos, avanzamos en la especificación de representaciones y prácticas de alterización hacia migrantes africanos que sin ser las únicas que hemos registrado son significativas por sus vínculos con el fenómeno de la invisibilización de la negritud y la afrodescendencia en la sociedad argentina: el desconocimiento social, el exotismo y la discriminación racial. Finalmente, en las conclusiones, se retoman las ideas que se quieren destacar $y$ poner en relación.

\section{Invisibilidad, apariciones y presencias}

Las representaciones sociales tienen anclaje en una configuración socio-histórica y otorgan sentido a la participación de los actores en un sistema de relaciones y jerarquías sociales. Las interacciones sociales habitualmente «ponen en juego" y destacan la diversidad de los interlocutores, ya sea que se trate de diferencias 
culturales, «raciales»³, sociales; y, eventualmente, también las desigualdades sociales. La literatura académica ha mostrado con argumentos que en la sociedad argentina las modalidades históricas de representación de la población africana y afrodescendiente, construida socialmente como negra con base en unos rasgos específicos (sobre todo en relación con el fenotipo. Frigerio, 2008), se han caracterizado por la negación e invisibilización social. La concepción eurocéntrica y «blanca» de la sociedad argentina ha sido (re)producida históricamente a nivel macro-social por agentes del Estado, a través de una narrativa dominante acerca de la nación, y a nivel micro-social por el discurso social, en las relaciones sociales propias de la vida cotidiana (Frigerio, 2008).

La construcción del Estado-nación en Argentina implicó su institución como un antagonista de las diferencias, interpelando a las personas y colectivos racial o étnicamente marcados (indios, africanos e inmigrantes, de manera diferenciada) a abandonar sus pertenencias en función de la producción de una homogeneidad cultural y como condición de acceso a la ciudadanía (Briones, 2005; Caggiano, 2005; Grimson, 2006; López, 2005; Segato, 2007). En relación con los afroargentinos esa desmarcación implicó su exclusión de los censos de población durante más de cien años (recién en el censo nacional del año 2010 se los volvió a contabilizar a esa parcialidad). Lo propio aportó a este proceso de desmarcación, negación y construcción de una invisibilidad de lo africano en la sociedad argentina la literatura nacional (Geler, 2012; Solomianski, 2003) En este contexto, es difícil concebir que la inserción social de los migrantes africanos arribados en las últimas décadas en la sociedad argentina pueda ser ajena a este marco histórico de invisibilidad de la población de origen africano y a los procesos macro y micro de construcción social de la blanquedad (Frigerio, 2008).

No obstante lo anterior, trabajos académicos recientes sostienen que en la década de 1990, precisamente cuando comenzó el arribo de una nueva corriente de migrantes del África subsahariana, se inició un cambio de régimen de visibilidad de la etnicidad y se produjo un pasaje "de una situación de invisibilización de la "diversidad" hacia una creciente hipervisibilización de las diferencias» (Grimson, 2006, p. 70). Para el caso de los afroargentinos, en particular, Frigerio (2008) observa el pasaje de una «casi total invisibilidad» durante el siglo XX a su «reaparición» o re-visibilización a partir de la década de 1990; cuando emergieron y confluyeron activismos políticos y culturales que ya operaban desde la década de 1980 (Domínguez, 2004; Frigerio y Lamborghini, 2011).

Una emergencia en el mismo sentido ha sido señalada específicamente para el caso de los afrodescendientes caboverdeanos (Maffia \& Ceirano, 2007).

La re-visibilización de los afrodescendientes, concretamente, tiene lugar en y por una coyuntura de creciente presencia en la arena pública, sobre todo en la década de 2000 , de militantes y organizaciones de este grupo, favorecida por las políticas de reconocimiento de la diversidad cultural de la nación (que han dado lugar, por ejemplo, a la declaración del Día Nacional de los Afrodescendientes y la Cultura Afro y al ya mencionado registro censal del año 2010). Paralelamente, el fenómeno migratorio del África subsahariana otorgó mayor visibilidad social y mediática (predominantemente en términos de «curiosidad» social) a la población «negra» en Argentina. No obstante los fenómenos conver- 
gentes a favor de la re-visibilización, que por otra parte son muy recientes como para producir variaciones significativas sobre la histórica invisibilización de las personas de origen africano en la sociedad argentina, el conocimiento de la experiencia de inserción social de migrantes caboverdeanos en la provincia de Buenos Aires, estudiada por Maffia (2010), entrega, a nuestro criterio, elementos de valor para pensar que el imaginario de la blanquedad argentina puede todavía incidir sustancialmente en la inserción y representaciones de los migrantes africanos recientes.. En definitiva, entendemos que la inserción de las nuevas presencias africanas en la sociedad argentina tiene lugar en una coyuntura en que los imaginarios instituidos prevalecen en puja con las representaciones que emergen como distintas. En este contexto se vuelve relevante conocer las construcciones de sentidos de los actores sociales, en interlocución.

\section{Identificaciones de los migrantes}

Si partimos de la idea, como aquí efectivamente lo hacemos, de que las identidades étnicas se construyen de manera relacional y son dinámicas porque se modifican situacional e históricamente (Chiriguini, 2008), tenemos que examinar las identificaciones de los migrantes senegaleses a la luz de sus trayectorias individuales previas y de sus relaciones sociales en el contexto migratorio.

Un senegalés que vivió en varios países de Europa occidental antes de establecerse en la ciudad de Buenos Aires, donde ejerce desde el año 2001 la enseñanza de música africana y donde participó en la formación de la Asociación de Residentes Senegaleses en Argentina, explicaba en una entrevista una idea sobre la identidad de los africanos que formaba parte de su imaginario antes de emigrar y que a menudo contrastaba con sus experiencias en el contexto migratorio local.

\footnotetext{
Porque a nosotros en el colegio, allá en África, nos hacían creer que después de la época de la esclavitud ya no existía más discriminación [dice de forma irónica]. En todos los colegios está escrito, arriba [en lo alto de una pared]: «La esclavitud es un crimen contra la Humanidad». En todos los colegios, entonces desde chiquito se te queda eso en la cabeza (Amadou, octubre 2011).
}

Con estas palabras, Amadou. trataba de explicar, diez años después de su arribo a Buenos Aires, que desde su perspectiva la persistencia del imaginario asociado a la esclavitud tenía algún valor explicativo respecto del lugar asignado a las personas de origen africano en el imaginario social local. Según este razonamiento, si afuera de África los africanos siguen siendo percibidos como ex esclavos no es extraño que sean discriminados.

Esa conciencia que expresaba Amadou sobre un imaginario negativo de África y de sus habitantes en los países no africanos receptores de migrantes africanos (sobre todo europeos, pero ahora también sudamericanos) pocas veces fue revelada con tanta claridad por los interlocutores de esta investigación. Tal vez porque entre ellos las trayectorias previas a la migración y las experiencias como migrantes han sido diversas, en parte por una disponibilidad diferente de recursos materiales y simbólicos. Pero, en la diversidad de experiencias y recursos, los migrantes interpelados referían recurrentemente a conocimientos comunes que permiten presuponer que quienes eligen la emigración como medio para la concreción de proyectos personales, familiares o comunitarios 
tienen, cuando menos, una imagen creada de la orientación dominante de las representaciones y las prácticas hacia los migrantes del mismo origen en el lugar de recepción. Esto aun considerando el mito del "paraíso en el extranjero», y otros vinculados a tal construcción simbólica, que Sayad (2010) define como «la mediación necesaria a través de la que puede ejercerse la necesidad económica» (p. 54).

La fórmula «¡No ser identificado es la llave del éxito!» ${ }^{4}$, que instruye a migrantes africanos dispuestos a ingresar a Europa, con el doble sentido que adquiere en este caso por alusión a la práctica de hacerse invisible o negar la propia identidad en un contexto social adverso, es demostrativa de que hay informaciones y (pre)supuestos compartidos que permiten a los migrantes prever el curso de los acontecimientos y actuar en consecuencia durante sus primeras interacciones en las sociedades de acogida.

En este sentido, algunas experiencias de investigadores extranjeros y locales entrevistados en el marco de nuestra investigación con el objetivo de conocer y poner en común el trabajo con este nuevo contingente de migrantes han confirmado la experiencia propia de ser eludido sistemáticamente por los migrantes durante un largo tiempo cuando se trataba de conocer informaciones personales sobre origen, composición familiar, situación documentaria, entre otras ${ }^{5}$.

Ahora bien, más allá de la manipulación de informaciones sobre cuestiones personales, que son extensibles a otros contextos migratorios y se vinculan fundamentalmente con la migración irregular, la cuestión de la identificación $^{6}$ de estos migrantes en la sociedad local presenta rasgos singulares asociados con el propio régimen de visibilidad de las alteridades africanas en Argentina. De ahí el asombro y la ironía que manifiesta Amadou en la cita anterior al advertir la incidencia de un imaginario de la esclavitud en la percepción local de los migrantes africanos.

Justamente, al examinar el trato que reciben migrantes negros de diferentes procedencias dedicados a actividades culturales en Buenos Aires, Domínguez (2004) sostiene que la invisibilización de los afrodescendientes en la sociedad argentina deriva para el caso de los migrantes en actitudes xenófobas, exotizantes, compasivas y favorece su extrañamiento y extranjerización. En sintonía con este argumento, agregamos que si la narrativa dominante de la composición étnico-«racial» de la nación ha negado históricamente la existencia del componente africano «negro», y si los grupos sociales reprimidos por ese fenómeno han apelado a la des-etnicización-racialización para fundirse en el «crisol de razas» y favorecer así su incorporación ciudadana (Geler, 2010; Solomianski, 2003), no resulta inconcebible que actualmente las presencias de origen africano produzcan extrañeza, allende la nacionalidad.

En el proceso de investigación hemos llegado a comprender que ese fenómeno (el extrañamiento frente a las personas negras de origen africano) es percibido por algunos migrantes en términos de una obturación de la percepción hacia la diversidad cultural y «racial». Así lo explicaba un senegalés dedicado al comercio internacional y radicado temporariamente en Buenos Aires, quien conocía por su trabajo varios países de Europa occidental, Asia, el África subsahariana y América del Sur: 
Argentina es un país especial, es el único país donde la gente te mira porque eres negro. Una vez le comente [esta situación] a un hermano que vive en Paris y él me preguntó si Argentina pertenece al mundo. En China, que tiene una cultura muy cerrada, nadie te mira. Para mí, esta situación es parte de la historia de Argentina, que ha exterminado su población negra para europeizarse (Mamadou, mayo 2010).

Esa idea de obturación (en el sentido de cerramiento) del imaginario social y cultural, que sugería Mamadou -y que se hace evidente en la extrañeza frente a las personas negras, es una percepción bastante común entre los migrantes que entrevistamos. De hecho, asumiendo esta representación hacia las personas de la sociedad argentina, algunos migrantes africanos dicen diferenciarse de los argentinos a partir de reconocer en sí mismos una «apertura en su visión de mundo», que sería el resultado y la ventaja de conocer distintas culturas.

\footnotetext{
Para mi Argentina es un país que se busca y no está todavía en la mundialización, necesita una grande abertura para poder competir en un mundo cada día más abierto [...] Hay que cambiar la mentalidad, comenzando con los programas de escuela para enseñar a la nueva generación de argentinos la riqueza de la diversidad (Mamadou, mayo 2010).
}

Yo de África fui a Argentina, después a Australia, Inglaterra, Uruguay, Estados Unidos, Holanda y París. Pero el sello de Argentina es como que ver un negro le espanta, como genera una curiosidad muy alta. Por ejemplo, acá ven un negro: “Oh mira», se tocan los codos y se ríen. Los adultos: “Mira, mira» (Celestín, junio 2012).

En efecto, la propia experiencia de aproximación a los migrantes africanos interpelados en el marco de la investigación estuvo marcada por presupuestos fundados en el desconocimiento, en general, de África y de la situación econó- mica, social, política de los países africanos de los que provenía esta migración. Pero también de los afroargentinos y de su pasado y presente en la sociedad argentina. La primera reflexión en este sentido surgió a partir de la advertencia de una joven migrante de origen senegalés, cuando apenas comenzaba el trabajo de campo en la ciudad de La Plata, quien a propósito de un presupuesto sobre las condiciones de vida en Senegal sentenció e interrogó: ¡Ay, tú no sabes nada sobre nosotros! ¿Qué piensas vos sobre nosotros? (Aminata, febrero 2008).

Llegados aquí, es preciso no pasar por alto lo que representa el término «nosotros» en las palabras de los migrantes entrevistados. Si se revisan las citas anteriores se puede establecer con cierta claridad que en las identificaciones asumidas frente a la sociedad de acogida los migrantes en general no apelan a diferenciaciones por nacionalidad al interior del colectivo «africanos» (senegaleses, nigerianos, etc.). En estos casos, los entrevistados apelan a adscripciones colectivas tales como «negros», evidentemente en correlación con las formas en las que son interpelados por las personas de la sociedad mayor. Nuestro trabajo de campo, no obstante, nos permite sostener ( $y$ aclarar al lector por obvio que sea) que en otros contextos de interacción las identificaciones de los migrantes en cuestión asumen otras pertenencias (étnicas, religiosas, de género, etc.). Más todavía, hasta donde se ha podido indagar, esas identificaciones advierten al analista sobre la poca pertinencia de pretender representar el colectivo africano o «afro" como un todo homogéneo e indiferenciado (es decir, como comunidad idéntica $)^{7}$. De hecho, los propósitos, relacionados pero no equivalentes, de luchar contra la discriminación racial y/o de difundir la «cultura» de cada colectivo nacional, para 
aportar a un conocimiento menos superficial de los mismos y luchar contra el racismo, han sido ya registrados como elementos de integración/ diferenciación/disputa presentes en situaciones de diálogo y articulación entre instituciones de afroargentinos, migrantes afrodescendientes y africanos (Lamborghini \& Frigerio, 2010; Zubrzycki, Agnelli, Ottenheimer \& Maffia, 2010).

Dicho lo anterior, es preciso cerrar esta parte dejando planteada una idea ya esbozada que sirve de introducción al siguiente apartado: que la obturación de la cosmovisión de «los argentinos» hacia la diversidad, en este caso de los africanos «negros» (que deriva tanto en espanto como en curiosidad hacia los individuos así uniformemente identificados) se relaciona con una herencia cultural histórica de negación y con un fenómeno de desconocimiento social hacia África y los africanos.

\section{Desconocimiento social}

El desconocimiento que advertimos en nuestra concepción individual al interactuar con migrantes, y que era más o menos puesto en palabras por estos como un problema de cosmovisión de la sociedad de recepción, parece ser en efecto un fenómeno social de amplio alcance que en la sociedad argentina toma una forma singular. En América y en Europa algunos militantes sociales y críticos del imaginario occidental eurocentrado han advertido con cierta ironía que «África no es un país», haciendo referencia así a la ignorancia occidental predominante respecto del continente africano ${ }^{8}$. En un contexto próximo, como el entorno social de las ciudades de Buenos Aires y La Plata no pocas personas se sorprenderían con esa aclaración. Evidencia de esto son algunas «confusiones» que hemos registrado en el trabajo de campo. Mamadou, por ejemplo, se mostró frustrado con el desconocimiento implícito en la respuesta de un comprador ocasional de bijouterie que le preguntó por su lugar de origen. En esa oportunidad, apelando a su doble ciudadanía (senegalesa y francesa) y a su conocimiento de los prejuicios sobre África, Mamadou respondió que procedía de Paris; pero los prejuicios y la ignorancia no dejaron lugar a dudas en su interlocutor: «Ah, París, África, iqué lindo!».

En el caso mencionado, si bien puede admitirse un problema de desconocimiento de geografía política, detectamos también una idée reçue (Amossy y Pierrot, 2010) ${ }^{9}$ en la sociedad argentina indicativa de que todos los negros proceden de África (o de otros países no europeos con gran número de población de origen africano). En forma concomitante, esa idea común sentencia que en Argentina los negros son extranjeros.

En particular, las interacciones y observaciones de campo durante nuestra investigación permitieron registrar múltiples manifestaciones (más allá de nuestra propia experiencia, ya mencionada) de un profundo desconocimiento social sobre África y los africanos en general ${ }^{10}$. Son ejemplo de lo anterior la confusión de África con un país, la imposibilidad de diferenciar las nacionalidades africanas, la presunción de que África es un continente habitado por sociedades primitivas, el prejuicio acerca que se trata de comunidades hambreadas, violentas y al margen del desarrollo tecnológico y del desenvolvimiento económico global.

Es posible que ese fenómeno (como así también el desconocimiento hacia los afroargentinos) sea una manifestación fáctica de la «represión» (o negación) de la negritud argen- 
tina (Solomianski, 2003). La situación descrita podría, por otra parte, fundamentar algunas percepciones marcadas por la incertidumbre hacia los migrantes. Según Grimson (2007), «una situación donde se multiplican los contactos entre culturas, entre universos simbólicos diferentes, pero donde prevalece un desconocimiento del otro, una profunda incomprensión, es una situación generadora de incertidumbre [...]». (p. 1). En el caso estudiado, de hecho, la manifestación del desconocimiento social durante las interacciones parecía producir cierto malestar en algunos migrantes y, en algunos casos, predisponerlos de manera negativa para la comunicación.

Nuestra propia experiencia, sin embargo, permite confiar en que la comunicación sostenida en una relación interpersonal de largo plazo puede ser la vía para fisurar los imaginarios viciados por la ignorancia y atados a muchas imágenes tergiversadas de África y de los africanos.

En síntesis, creemos que el aludido fenómeno del desconocimiento social tiene un carácter colectivo, compartido y co-construido en la sociedad argentina, con base en la represión de la negritud argentina y en la desinformación o la información sesgada y acotada por el imaginario euro-occidental sobre África. En forma concomitante, la ignorancia social acerca de lo africano, consecuente de la pretendida blanquedad argentina, facilita tanto la reproducción de imágenes estereotipadas como la construcción exotista de los africanos.

\section{Exotismo: la sensación de ser una «pieza de zoológico»}

Las relaciones sociales de los migrantes africanos en la sociedad argentina dejan ver modalidades específicas de representación que han merecido nuestra atención, referimos al exotismo y la exotización. En pos de clarificar estos dos conceptos hay que decir que en la experiencia del exotismo el sujeto tiene la capacidad de extrañarse y sentir placer por lo diverso. En favor de salvaguardar esa vivencia y preservar la alteridad, el sujeto es capaz también de bloquear la asimilación del objeto (Segalen, 2002; Todorov, 2005). Ahora bien, una delgada línea separa el extrañamiento y el goce de la diversidad de la asimilación o la incomprensión fundada en el etnocentrismo. Una de las consecuencias del asimilacionismo exotista se puede inferir de una enunciación afirmativa de Mametoo Kiamasi, responsable del programa «Afrodescendientes» del INADI"11:

\begin{abstract}
Vengo aquí a representar lo que soy, una mujer afroargentina, orgullosa de serlo. Nosotros como afro tenemos un legado, que son los aportes que hicimos en la historia, la cultura y la lengua de la Argentina. No somos una minoría ni un objeto exótico, si no co-hacedores de la Argentina junto a otros colectivos (INADI, 2012b, párr. 8).
\end{abstract}

El compromiso en este caso de Kiamasi en contrarrestar las representaciones de lo «afro» como exótico y minoritario (reducido a una diferencia cultural, «racial») se articula en un reclamo contra el imaginario social dominante que históricamente ha negado a los afroargentinos y sus aportes a la identidad nacional porque se trata, efectivamente, de dos facetas del mismo problema. En este contexto, la exotización puede entenderse como una forma de representación que focaliza y sobredimensiona 
las diferencias y reduce al Otro a algunos rasgos (físicos, psíquicos, culturales) socialmente definidos como característicos o naturales y concebidos como una esencia. Así concebida, la diferencia puede constituir una barrera crucial para la comunicación y la integración social (Morales, 2005; Archenti \& Morales, 2009; Archenti, Courtis \& Morales, 2011) ${ }^{12}$.

Algunos estereotipos y prejuicios registrados durante nuestro trabajo de campo tienen relación con la exotización, como la idealización de los cuerpos de los varones y mujeres negros/ as en términos de voluptuosos y bien dotados y su percepción como objeto sexual. Asimismo, hemos presenciado situaciones y recogido testimonios de ofrecimientos de diverso tipo, confusiones y malentendidos con base en presupuestos sobre la sexualidad de los migrantes africanos (varones y mujeres). La extensión de las ideas de hipersexualidad de los negros en la sociedad argentina ha sido asumida por el INADI (2012a), que en un informe sobre buenas prácticas en la comunicación pública ha recomendado a periodistas y profesionales de la comunicación evitar la cosificación de los afrodescendientes a través de la habitual asociación de la negrura con una mayor potencia o predisposición sexual.

Por otra parte, la admiración o fascinación por la piel de las personas «negras», que se manifiesta en situaciones cotidianas de interacción de los migrantes africanos, y la concepción de estas, en algunos casos, como objeto de observación y señalamiento discriminatorio, no es ajena a la construcción exotista. En efecto, la «sensación» de ser una «pieza de zoológico» (Baakir, marzo 09) nos fue manifestada con estas $u$ otras palabras por varios de los interlocutores migrantes.

\section{Discriminación racial}

A diferencia de la migración caboverdeana, que por algunas investigaciones sabemos que trasladó a la sociedad argentina las prácticas de invisibilización de la afrodescendencia dominantes en los territorios de origen (Maffia \& Ceirano, 2007; Maffia, 2010), las nuevas presencias africanas que asumen para sí la condición socialmente construida de ser «negros» y «africanos» contrastan, por medio de sus hetero y auto representaciones, la pretendida blanquedad nacional argentina. Ahora bien, ¿qué actitudes emergen en las interacciones sociales cuando aquellos componentes sociales, culturales, «raciales» siempre negados como propios (la afrodescendencia, el fenotipo «negro») irrumpen entre «Nosotros»? Algunas experiencias relatadas por migrantes entrevistados entregan evidencias de prácticas discriminatorias:

Por ahí uno no ve y el otro le señala [...] un negro [...] O vienen y te tocan, a mí me pasó eh [...] estaba en la guardia del Hospital Argerich, acababa de llegar, en el 95 , no entendía nada [...] alguien vino y me tocó. ¿Qué pasa [...]?, pregunté.

Me dicen: «No, es que tocar a un negro trae suerte». Se burlan [...] así, abiertamente.

Hasta el día de hoy sigue pasando, pero no tanto porque de a poco se van acostumbrando. O tal vez ya lo asimilé y no lo veo tanto. Los nuevos lo ven más (Celestín, junio 2012).

Si uno va sabiendo el idioma ahí te das cuenta de lo que son. Sabiendo el idioma escuchas de todo. Donde vos entras [...] dos argentinos te hacen chistes [...] Entendés, no te lo dicen directamente, pero vos sabes que el chiste ese es tuyo. El chiste es para vos. A eso yo lo sentí un montón de veces (Abba, agosto 2010).

Llegados a este punto cabe mencionar una conclusión a la que llega Bidaseca (2010) con base en los resultados de una encuesta socio-cultural-demográfica (que interrogaba sobre discriminación) aplicada a migrantes afri- 
canos, afrodescendientes extranjeros y afroargentinos de la ciudad de Buenos Aires (Bidaseca, 2010) $)^{13}$. Según los autores, la mayoría de los migrantes entrevistados contestaron que nunca habían sufrido una práctica discriminatoria, al tiempo que mostraban cierta actitud hacia la naturalización del racismo y una negación de sus pertenencias africanas.

Por un lado, observamos la naturalización del racismo cotidiano, la objetualización de los vendedores ambulantes africanos que son parte del paisaje citadino (un encuestado por ejemplo, afirmó que «cotidianamente era insultado por su color de piel, pero que prefería no pensar en ello", Encuestadora). Paradójicamente, se presenta la autonegación mientras el estereotipo con el cual se la/os violenta sigue siendo el color de la raza: «Negra de mierda...», "Negro de mierda, volvete a tu país» (Relato de una entrevistada) (Bidaseca, 2010, p. 28-29).

No obstante la validez de este planteo que enlaza discriminación y "auto-negación», en nuestra perspectiva, el problema puede ser todavía más complejo. El caso de las «identidades negativas", en tanto ocultamiento de la pertenencia a grupos discriminados, puede ser una estrategia para evitar sufrimientos mayores (Chiriguini, 2008). No es extraño, entonces, que el informe antes citado acuse que buena parte de los migrantes africanos y afrodescendientes encuestados en Buenos Aires niega tener algo que ver con África y los africanos (Bidaseca, 2010). Por otra parte, cuando frente a los investigadores los migrantes niegan cualquier hecho de discriminación, algo detectado con frecuencia en las primeras entrevistas con nuestros interlocutores africanos, se vuelve necesario reflexionar sobre las técnicas y la propia pregunta de investigación.
Sobre lo anterior entregan una clave los dichos de Celestín, un migrante de la República Democrática del Congo, con conocimiento de esta problemática por su militancia en una organización de la sociedad civil que él mismo fundó en la ciudad de Buenos Aires:

\begin{abstract}
En el imaginario argentino, fíjate en el campo político, los funcionarios públicos, los grandes representantes de las empresas privadas, responden al imaginario europeo. Hay bolivianos nacidos acá, tendrán 50 años, abogados, licenciados... pero no existen en el liderazgo en el sector político o privado. Es como funciona el racismo en Argentina... Si vamos a los afros y a los indios el plan fue aniquilarlos, no se logró totalmente, pero la Campaña del Desierto I y II apuntaron a los indios, que hasta el día de hoy los indios son personas que viven como si no tuvieran derechos [...] La forma de evaluar el racismo es [considerar el] acceso a derechos (políticos, civiles, económicos, sociales y culturales) [...] Tomemos la nueva inmigración africana. Entre ellos hay profesionales universitarios ¿Cuántos lograron un trabajo acorde a su preparación profesional?... entonces, es ahí donde funciona el racismo (Celestín, junio 2012).
\end{abstract}

Se hace evidente entonces que preguntar por discriminación debiera implicar interrogar por el acceso a derechos. Posiblemente donde se manifiesta la negación de la discriminación sea viable registrar la falta de acceso o el ejercicio desigual en relación con derechos adquiridos por la ciudadanía. En relación con los senegaleses en Argentina, Cullenward (2009) sostiene que «ellos no hablan acerca de las limitaciones de acceso a la asistencia médica ni educación ni otros derechos fundamentales porque ellos no tienen mejor acceso en Senegal» (p. 91). No obstante, esa afirmación no está debidamente fundamentada por la autora; y contrasta con manifestaciones públicas de migrantes africanos que en entrevistas difundidas en medios de comunicación nacionales y extranjeros han 
expuesto modalidades de discriminación y reclamos al Estado argentino para que garantice una mejor inserción en el contexto local ${ }^{14}$.

Al respecto es clarificador el planteo de representantes de la Asociación Civil África y su Diáspora, que agrupa a afrodescendientes de la Ciudad de Buenos Aires, sobre los espacios sociales en que se hace evidente la vulnerabilidad de los afrodescendientes:

\begin{abstract}
En Argentina se mantienen las condiciones de vulnerabilidad social en las distintas comunidades afro, determinando las diferencias en el ingreso económico, el acceso a la educación, el trabajo, la representación política, entre otras variables [...] Este informe [Perspectivas socioculturales y sociodemográficas de la población afrodescendiente y africana de la CABA] muestra que las concepciones discriminatorias y represivas siguen moldeando los comportamientos en especial de las fuerzas policiales y también de los organismos públicos y espacios laborales (Bidaseca, 2010, pp. 5-6).
\end{abstract}

Un informe anterior al antes citado, realizado en el marco de un diagnóstico sobre discriminación por el INADI en el año 2005, clasifica la discriminación sufrida por los afrodescendientes en la sociedad argentina según tres espacios sociales donde es posible registrarla: en los establecimientos educativos; en los medios de comunicación; y en los ámbitos hospitalarios $^{15}$. Según el informe del INADI, en el espacio educativo la discriminación se concreta a través de la reproducción de la invisibilización en las prácticas docentes y por asociación, en los contenidos curriculares, de la presencia «negra» solo con la esclavitud y con la época colonial. En los medios opera a través del «exotismo» y del tratamiento de las personas africanas o afrodescendientes como «objetos sexuales». Mientras que en el espacio de la salud pública se ha detectado un trato dife- rencial y mediado por prejuicios, al asociar a la comunidad «negra» con algunas enfermedades que le serían propias.

Los representantes de grupos afrodescendientes consideran que la situación de marginalidad heredada de la época de la colonia se mantiene: como durante el siglo XIX, sus ocupaciones continúan siendo subalternas y es habitual que vivan en viviendas precarias. Sumado a esto, muchas madres son Jefas de Hogar y el nivel de escolaridad es bajo. [...] Asimismo, denuncian trato discriminatorio en los ámbitos laborales (acoso, burlas, paternalismo humillante, etc.) y persecución policial (INADI, 2005, p. 125).

Es importante agregar a lo dicho que en el marco de nuestra aproximación a los migrantes africanos hemos registrado una tendencia general hacia el evitamiento del uso de servicios públicos o de las consultas a funcionarios públicos por temor a dificultades en la comunicación, a la persecución por irregularidad documentaria y/o al trato discriminatorio por intermedio de la imposición de la burocracia administrativa ${ }^{16}$. De hecho, en ocasiones de presentación ante entidades públicas para realizar trámites burocráticos (en particular, relativos a documentación) algunos de nuestros interlocutores migrantes solicitaban ser acompañados por una persona perteneciente a la sociedad local por considerar que su intervención podía ser favorable.

En síntesis, puede decirse que las prácticas discriminatorias y las representaciones negativas hacia los migrantes africanos recientes muestran una continuidad con el imaginario de la invisibilidad afroargentina, no tanto por una orientación hacia la represión del componente africano sino porque prevalecen las desigualdades en el plano del ejercicio de los derechos. 


\section{Conclusiones}

En relación con la primera de las problemáticas que propusimos desarrollar en este artículo, las identificaciones de los migrantes en el contexto de su inserción en las ciudades de Buenos Aires y La Plata, estamos en condiciones de afirmar que esta cuestión no se puede abordar sin establecer una relación contextual directa con el proceso de invisibilización de los africanos y sus descendientes en Argentina. En esa línea de ideas, mostramos que las adscripciones de nuestros interlocutores se construyen oposicionalmente y en tensión con un imaginario social dominante en la sociedad de recepción que representa a las personas socialmente construidas como negras $y$ de origen africano en términos de diferentes, exóticas, y objeto de discriminación. Los migrantes conocen o pueden advertir las representaciones negativas hacia ellos en la sociedad de acogida y asumen pertenencias o despliegan estrategias de evasión situacionales. Asimismo, en algunos casos, elaboran interpretaciones acerca de la extrañeza que produce su presencia en el contexto migratorio y plantean en términos críticos la idea de una obturación del imaginario nacional (blanco y eurocentrado) que niega la negritud argentina y desconoce la riqueza de la diversidad y la interculturalidad.

Por otra parte, en lo que refiere a las representaciones que en la sociedad argentina construyen a los migrantes como Otros, hay que decir que, tal como lo planteamos desde el principio, el desconocimiento social acerca de África y los africanos, el exotismo, y la exotización con base en las diferencias (de fenotipo, culturales) están enlazados con la histórica invisibilidad (social, cultural) de la negritud y la afrodescendencia argentina. En particular, el desconocimiento social que se manifiesta respecto de lo relativo al continente africano, a los migrantes de ese origen y a los afrodescendientes en general, podría estar vinculado con una represión o negación de carácter histórico de la presencia de esclavos y negros libres en Argentina. Esa misma negación es condición de posibilidad para las representaciones exotistas de las personas «negras», africanos y afrodescendientes (Domínguez, 2004). Al respecto, argumentamos que a menudo el exotismo hacia las personas de fenotipo negro, entendido como contemplación y goce de las diferencias, toma la forma de una esencialización y reducción del Otro con base en las diferencias socialmente construidas, en contextos de desigualdad social.

Las asimetrías sociales que afectan a los migrantes africanos se hacen evidentes en las prácticas discriminatorias que sufren cotidianamente en distintos espacios sociales y en las restricciones en el acceso a derechos, que testimonian algunas experiencias que hemos recogido y que han sido también documentadas en informes de organizaciones civiles e instituciones académicas (Bidaseca, 2010) y de organismos públicos (INADI, 2005, 2012a). Un contexto social adverso, en el sentido señalado, puede contribuir en algunos casos a la auto-negación de las pertenencias africanas o afrodescendientes (que han registrado otros estudios. Bidaseca, 2010) o al evitamiento de las relaciones sociales donde se manifiestan las desigualdades. En las prácticas discriminatorias, en definitiva, como en las representaciones antes descritas, podemos verificar la incidencia de la invisibilización de la negritud y la afrodescendencia argentina, en tanto manifestaciones de una segregación y desigualdad históricamente construidas. 
Llegados a este punto, es preciso señalar que los problemas aquí tratados merecen mayor atención de las investigaciones que actualmente se interesan por el fenómeno migratorio africano, no solo para conocer la recepción y las relaciones de los migrantes en la sociedad argentina sino también para comprender mejor el imaginario de la blanquedad y el proceso de invisibilización social de los afrodescendientes.

\section{Notas}

${ }^{1}$ La investigación en cuestión reunió un corpus heterogéneo de materiales de análisis que no viene al caso especificar, pero vale decir que permitió un análisis amplio del problema atendiendo a múltiples espacios sociales de producción y circulación de representaciones sociales acerca de los africanos y los afrodescendientes (interacciones sociales con participación migrantes, medios de prensa, medios sociales de organizaciones de migrantes africanos y de afrodescendientes).

${ }^{2}$ Retomamos esta noción de Alioua (2008) para referir a los intercambios, negociaciones y demandas de servicios en el contexto de una etnografía que implica redes de relaciones densas con poblaciones migrantes.

${ }^{3}$ Usamos este término para referir al concepto social de raza, es decir, para hacer alusión a lo que es construido socialmente como raza.

${ }^{4}$ «N'être pas identifiable est la clé du succès!!!», en el original (la traducción es nuestra). La referencia corresponde a un instructivo publicado en el sitio Web Planete-senegal.com dirigido a migrantes africanos que estén dispuestos a navegar en canoa para acceder por mar a territorio español de manera irregular. Véase: «Venir en Europe: mode d'emploi» (Planete-senegal.com, 2006).

${ }^{5}$ Esta migración atrajo el interés en el campo académico nacional y también de numerosos jóvenes cientistas sociales de países europeos que han hecho estadías de investigación en Buenos Aires para indagar este fenómeno migratorio. Algunos de estos investigadores participaron en una instancia de intercambio, socialización y reflexión sobre la problemática de las identificaciones en el trabajo etnográfico en el marco del II Conversatorio «Identidades y Sujetos. Interculturalidad en el trabajo etnográfico con africanos y afrodescendientes", realizado el 2 de julio de 2012 en el Instituto de Investigaciones en Comunicación de la Facultad de Periodismo y Comunicación Social de la Universidad Nacional de La Plata. Algunas experiencias expuestas y discusiones dadas en ese espacio se recogieron luego en una publicación (Morales \& Ledesma, 2013).

${ }^{6}$ Opto aquí por esta noción en tanto que representa una alternativa a las conceptualizaciones objetivistas-esencialistas de la identidad social, focaliza a los agentes que producen la identificación y establece una ruptura respecto del presupuesto de homogeneidad identitaria (Brubaker \& Cooper, 2005).

${ }^{7}$ Hay que destacar que, salvo en el caso de militantes y referentes de organizaciones civiles de migrantes, la dinámica de interacción cotidiana de los africanos que entrevistamos y acompañamos en sus actividades laborales no incluía interlocutores afroargentinos o afrodescendientes en general.

${ }^{8}$ Véase por ejemplo el blog África no es un país, del periódico español El País.

${ }^{9}$ Según Amossy y Pierrot (2010), las idées reçues «constituyen las evidencias básicas de una sociedad que describe su norma de conducta y sus creencias como un fallo universal» (p. 28).

${ }^{10} \mathrm{El}$ desconocimiento de las personas de la sociedad argentina sobre África también ha sido aludido, como un aspecto llamativo, por migrantes entrevistados en medios de comunicación locales. Véase: «Refugiados en Argentina - Perseguidos o Discriminados» (Todo Noticias, 2009).

11 Instituto Nacional contra la Discriminación, la Xenofobia y el Racismo. Creado por ley en 1995, el INADI es un organismo estatal nacional que tiene como fin combatir la discriminación en todas sus formas.

12 El exotismo y la exotización respecto de los migrantes senegaleses ha sido tratado con más detenimiento en un trabajo anterior en co-autoría, que expone más material de análisis que el que se refiere aquí (Morales \& Kleidermacher, 2015).

${ }^{13}$ La muestra elaborada para ese estudio estuvo conformada por 257 personas, de las cuales el 53 por ciento eran africanos/as y 47 por ciento afrodescendientes.

$1^{4}$ En otros trabajos del autor se han examinado los discursos de algunas organizaciones de migrantes y afrodescendientes de Buenos Aires, con especial atención en la auto-afirmación, los reclamos al Estado y la denuncia social (Morales, 2014b; Morales \& Maffia, 2016). Véanse también: «African Immigrants Turn to Argentina for Opportunity» (VJ Movement, 2009); «Refugiados en Argentina Perseguidos o Discriminados», (Todo Noticias, 2009); «Entrevista a Celestín Nengumbi Sukama», (La Colectiva Radio, 2011).

${ }^{15}$ El discurso de algunos medios de prensa de la ciudad de Buenos Aires y La Plata sobre los migrantes africanos y los afrodescendientes ha sido analizado en un trabajo anterior del autor, con especial atención en los temas asociados con estos grupos, las categorías de clasificación y los modos de representación de los mismos (Morales, 2015).

${ }^{16}$ El evitamiento (o evitación) -acción y efecto de evitar- es tratado por Goffman (1970) como una estrategia para evitar los encuentros sociales donde puede manifestarse el peligro de un conflicto en el plano de las representaciones. 


\section{Referencias bibliográficas}

Alioua, M. (2008). Àla rencontre de la sociologie d'Alain Tarrius. Du paradigme de la mobilité au territoire circulatoire. E-migrinter, (1), 7-19.

Amossy, R. \& Herschberg, A. (2010). Estereotipos y clichés. Buenos Aires: Eudeba.

Archenti, A. \& Morales, O. (2009). Selección excluyente y valoración: migrantes extranjeros en la prensa escrita local. En Verano, A. (Ed.), Medios de comunicación en la Argentina. Diagnóstico y prospectiva, t. II (pp. 19-40). La Plata: Ediciones de Periodismo y Comunicación № 40.

Archenti, A., Courtis, C. \& Morales, O. (2011). Tendencias en las representaciones de migrantes coreanos y chinos en la prensa gráfica argentina. En Courtis, C. \& Pacecca, M. I. (comp.), Discriminaciones étnicas y nacionales. Un diagnóstico participativo (pp. 163-174). Buenos Aires: Editores del Puerto.

Bidaseca, K. (Dir.) (2010). Perspectivas socioculturales y sociodemográficas de la población afrodescendiente y africana de la CABA. Buenos Aires: UBA-Asociación Civil África y su Diáspora.

Briones, C. (2005). Formaciones de alteridad: Contextos globales, procesos nacionales y provinciales. En Briones, C. (Comp.), Cartografías argentinas: políticas indígenas y formaciones provinciales de alteridad (pp. 9-40). Buenos Aires: Antropofagia.

Brubaker, R. \& Cooper, F. (2005). Más allá de «identidad». En Wacquant, L. (Coord.), Repensar los Estados Unidos: para una sociología del hiperpoder (pp. 178-208). Barcelona: Anthropos.

Caggiano, S. (2005). Lo que no entra en el crisol. Buenos Aires: Prometeo.

Cullenward, L. (2009). La inmigración africana a España y Argentina en la época de la globalización. (Tesis inédita de honor). Departamento de Estudios Hispánicos del Macalester Collage, St. Paul.

Chiriguini, M. (2008). Identidades socialmente construidas. En Chiriguini, M. (Comp.), Apertura a la antropología (pp. 61-78). Buenos Aires: Proyecto.

Domínguez, M. (2004). O "afro" entre os imigrantes em Buenos Aires: reflexões sobre as diferentas. (Tesis inédita de Maestría) Universidad Federal de Santa Catarina, Florianópolis.

Frigerio, A. (2008). De la «desaparición» de los negros a la «reaparición» de los afrodescendientes: comprendiendo la política de las identidades negras, las clasificaciones raciales y de su estudio en la Argentina. En Lechini, G. (Comp.), Los estudios afroamericanos y africanos en América Latina: herencia, presencia y visiones del otro (pp. 117-144). Córdoba: CEA - Buenos Aires: CLACSO.

Frigerio, A. \& Lamborghini, E. (2011). (De) mostrando cultura: estrategias políticas y culturales de visibilización y reivindicación en el movimiento afroargentino. Boletín Americanista, (63), 101-120.

Geler, L. (2010). Andares negros, caminos blancos: afroporteños, Estado y Nación. Argentina a fines del siglo XIX. Rosario: Prohistoria Ediciones; Barcelona: TEIAA (Universidad de Barcelona). (2012). «Hijos de la patria»: tensiones y pasiones de la inclusión en la nación argentina entre los afroporteños a fines del siglo XIX. Memoria Americana, 20 (2), 273-294.

Ghasarian, C. (2008). Por los caminos de la etnografía reflexiva. En Christian Ghasarian et. al., De la etnografía a la antropología reflexiva (pp. 9-42). Buenos Aires: Ediciones del Sol.

Goffman, E. (1970). Ritual de la Interacción. Buenos Aires: Tiempo Contemporáneo.

Grimson, A. (2006). Nuevas xenofobias, nuevas políticas étnicas en Argentina. En Grimson, A. \& Jelin, E. (Comp.). Migraciones regionales hacia Argentina. Diferencia, desigualdad y derechos (pp. 69-97). Buenos Aires: Prometeo.

(2007). Resguardar nuestra incerteza acerca de la incertidumbre. Debates acerca de la interculturalidad y la comunicación. Diálogos de la comunicación, (75), 1-7.

Instituto Nacional contra la Discriminación la Xenofobia y el Racismo (INADI) (2005). Hacia un plan nacional contra la discriminación: la discriminación en Argentina. Buenos Aires: INADI. (2012a). Buenas Prácticas en la Comunicación Pública. Informe Afrodescendientes. Buenos Aires: INADI. (2012b). Apertura del Seminario Argentina - Brasil de diálogo y cooperación sobre políticas Afro. Archivo Prensa INADI, 8 noviembre de 2012 Recuperado de: http://www.inadi.gob.ar/ archivo/?p=14590.

Katzer, M. \& Morales, O. (2009). Las "situaciones de comunicación" en el trabajo etnográfico. Reflexiones sobre la base de experiencias de campo. Oficios Terrestres, (24), 151-161.

La Colectiva Radio (2011). Entrevista a Celestín Nengumbi Sukama. Baldosas Flojas, FM 102.5, 31 de enero de 2011. Disponible en: www.youtube.com/watch?v=s1PB_GiJJMs. Fecha de consulta: 30 de diciembre de 2012.

Lamborghini, E. \& Frigerio, A. (2010). Quebrando la invisibilidad: Una evaluación de los avances y las limitaciones del activismo negro en Argentina. El Otro Derecho, (41), 139-166.

López, L. (2005). “¿Hay alguna persona en este Hogar que sea Afrodescendiente?”, Negrociaçoes e disputas políticas em torno das classificaçoes étnicas na Argentina. (Tesis inédita de Maestría). Universidad Federal de Rio Grande do Soul, Porto Alegre.

Maffia, M. (2010). Desde Cabo Verde a la Argentina. Migración, parentesco y familia. Buenos Aires: Biblos.

Maffia, M. \& Ceirano, v. (2007). Estrategias políticas y de reconocimiento en la comunidad caboverdeana de Argentina. Contra Relatos desde el Sur. Apuntes sobre África y Medio Oriente, 3 (4), 81-107.

Morales, O. (2005). El discurso exotizante: el caso del barrio chino en la prensa nacional. Revista Tram(p)as de la Comunicación y la Cultura, 4 (42), 30-37.

(2014a). Representaciones de alteridades "negras", africanas y afrodescendientes en la sociedad nacional en Argentina. Primera década del siglo XXI. (Tesis inédita de Doctorado) Universidad 
Nacional de La Plata, La Plata.

(2014b). Hacer visible aquello invisibilizado. Discursos de instituciones de afrodescendientes y migrantes africanos en Argentina. Tabula Rasa, (21), 305-323.

(2015). Si hay negros, que no se diga, si hay racismo, que se disimule. Migrantes africanos y afrodescendientes en la prensa argentina. Interscience Place, 4 (10), 81-106.

Morales, O. \& Ledesma, L. (2013). Identidades e interculturalidad en etnografías reflexivas. La Plata: Universidad Nacional de La Plata.

Morales, O. \& Kleidermacher, G. (2015). Representaciones de migrantes senegaleses en la sociedad porteña de Buenos Aires. Apuntes sobre exotismo y exotización. Etnográfica, 19 (1), 29-50.

Morales, O. \& Maffia, M. (2016). Configuraciones y articulaciones de organizaciones de afrodescendientes y migrantes africanos de Argentina. Una aproximación desde sus medios sociales. Revista Pós Ciências Sociais. RePOCS, 13 (26), 243-264.

Planete-senegal.com (2006). Venir en Europe: mode d'emploi, 9 de junio de 2006. Recuperado de: http://www.planete-senegal.com/ senegal/venir_en_france.php. Fecha de consulta: 19 de junio de 2017.

Sayad, A. (2010). La doble ausencia. De las ilusiones del emigrado a los padecimientos del inmigrado. Barcelona: Anthropos.
Segalen, V. (2002). Essay on Exoticism. Durham \& London: Duke University Press.

Segato, R. (2007). La Nación y sus Otros. Raza, etnicidad y diversidad religiosa en tiempos de políticas de la identidad. Buenos Aires: Prometeo.

Solomianski, A. (2003). Identidades secretas: la negritud argentina. Rosario: Beatriz Viterbo.

Todo Noticias (2009). Refugiados en Argentina: Perseguidos o Discriminados. Argentina para Armar, 23 de agosto de 2009. Disponible en: https://tn.com.ar/sociedad/\%C2\%BFperseguidos-odiscriminados_004897. Fecha de consulta: 30 de diciembre de 2012.

Todorov, T. (2005). Nosotros y Los Otros. México D.F.: Siglo XXI.

VJ Movement (2009). African Immigrants Turn to Argentina for Opportunity. World in Exodus: People on the Move, 19 de noviembre de 2009. Disponible en: http://www.vjmovement.com/truth/523. Fecha de consulta: 30 de diciembre de 2012.

Zubrzycki, B., Agnelli, S., Ottenheimer, A. \& Maffia, M. (2010). La diáspora africana en Buenos Aires (Argentina). En Santana, A. (Presidencia). Il Coloquio Afroamérica. Historia, Cultura y procesos Identitarios. Contra la invisibilización. Los afros y el Estado-Nación en América Latina. Universidad Autónoma de México, México DF. 